\title{
REVIEW
}

\section{Improving the Livelihood of Livestock and Farmers and Public Health in Developing Countries through the Provision of Solutions for the Various Risks They Face}

\author{
Kohei MAKITA $^{1 *}$, Munenobu IKEGAMI ${ }^{2}$ and Tomoya MATSUMOTO ${ }^{3}$ \\ ${ }^{1}$ Department of Veterinary Medicine, School of Veterinary Medicine, Rakuno Gakuen University, \\ Ebetsu, Japan \\ ${ }^{2}$ Department of International Economics, Faculty of Economics, Hosei University, Machida, Japan \\ ${ }^{3}$ Department of Economics, Otaru University of Commerce, Otaru, Japan
}

\begin{abstract}
Livestock plays an important role in the livelihoods of livestock farmers of developing countries through the provision of food, income sources, and assets. The International Livestock Research Institute (ILRI) has led global efforts on livestock research in developing countries, mainly in South and Southeast Asia and sub-Saharan Africa, and contributed to poverty alleviation and improvement of the health of people. During ILRI's over 50-year history, its research priorities and orientations have evolved from animal breeding, production and health to approaches addressing various risks faced by resource-poor livestock farmers. This review highlights the research work implemented by three Japanese scientists, who respectively evaluated or proposed innovative solutions to distinctive risks faced by livestock, agricultural farmers, and consumers in developing countries. They are namely, (1) Index-Based Livestock Insurance (IBLI) to counter climate change risks, (2) mobile money to livelihood risks, and (3) participatory risk analysis to food contamination. This review then identifies and discusses areas of further research needed to improve the livelihoods of livestock farmers, then concludes by calling for international collaboration.
\end{abstract}

Discipline: Animal Science

Additional key words: ILRI, Index-Based Livestock Insurance, mobile money, participatory risk analysis

\section{Introduction}

Livestock provides livelihoods and incomes for at least 1.3 billion people globally and plays a vital role in the livelihoods of livestock farmers in developing countries in Asia and Africa through the provision of food, income sources, and assets (ILRI 2021).

The International Livestock Research Institute (ILRI) has led global efforts on livestock research in developing countries, mainly in South and Southeast Asia and subSaharan Africa, and contributed to poverty alleviation and improvement of people's health. In the course of the ILRI's history of more than 50-years, its research priorities and orientations have evolved from animal genetics, production and health - particularly lethal tropical diseases affecting livestock to approaches addressing various risks faced by resource-poor livestock farmers. This review highlights the research work implemented by three Japanese scientists, who evaluated or proposed innovative solutions to the unique risks faced by livestock farmers. The solutions include (1) index-based livestock insurance (IBLI) to counter climate change risks, (2) mobile money for livelihood risks, and (3) participatory risk analysis of food contamination. This review then identifies and discusses areas of further research needed to improve livestock farmers' livelihoods and concludes by calling for international collaboration.

\section{History of ILRI}

1. The evolution of the ILRI's research priorities and orientation

ILRI (1994 till date) and its two predecessors,

*Corresponding author: kmakita@rakuno.ac.jp

Received 1 February 2021; accepted 20 August 2021. 
the International Laboratory for Research on Animal Diseases, based in Kenya (ILRAD, 1973 - 1994), and the International Livestock Centre for Africa, based in Ethiopia (ILCA, 1974 - 1994), have been dedicated to research on livestock in developing countries for nearly half a century, to address continuously emerging challenges, such as diseases, rangeland/grassland management, forage, and livelihoods, since the global famine began to recede, by the historical success of the Green Revolution by the CGIAR (formerly the Consultative Group of International Agricultural Research) (Smith 2020). In the following, the evolution of the ILRI's research priorities and orientations are briefly reviewed.

In its early years, since the time of the ILRAD and ILCA, the ILRI emphasized animal genetics (Rege et al. 2020), production (Ericksen et al. 2020, Hanson et al. 2020, Duncan et al. 2020, Blümmel et al. 2020, McIntire et al. 2020) and health - particularly for lethal tropical diseases affecting livestock. Livestock diseases significantly affect the stability of production systems, and zoonotic diseases further jeopardize the health of poor farmers and consumers. The ILRI tackled with East Coast Fever (Toye et al. 2020), a lethal tick-borne protozoan disease in young cattle, and neglected zoonoses such as African trypanosomiasis, which infects domestic and wildlife species and humans (Black 2020, Grace et al. 2020a). The ILRI contributed to understanding of the ecology, immunology, epidemiology, and economics of such important diseases and offered several practical solutions. Transboundary diseases cause significant damage to the economy, and the ILRI contributed to developing the global capacity of epidemiology and economics for important diseases such as Rinderpest and foot-and-mouth disease, and also the first global eradication of animal disease, Rinderpest (ILRI 2010). Early works of the ILRI focused on the management of rangelands/grasslands. With the increasing threat of climate change, livestock production has received greater attention as an emitter of greenhouse gases. Furthermore, climate change poses critical risks to the lives and livelihoods of poor people who remain dependent on livestock, particularly in Africa. To improve stability in securing forage for livestock in dry areas, ILRI worked closely with the International Crops Research Institute for the Semi-Arid Tropics (ICRISAT) and the gene banks of the International Center for Tropical Agriculture (CIAT) and the International Center for Agricultural Research in the Dry Areas (ICARDA) since its functioning as ILCA/ILRAD (Hanson et al. 2020).

In recent years, sustainable production that ensures the health of humans, animals, and the environment has become important. Therefore, understanding the socioeconomics of smallholder farmers and value chains is paid attention to along with technical intensifications such as livestock breeding, feeding, and management. Moreover, livestock research has started focusing on how innovative solutions can address the livelihood risks faced by livestock farmers. For example, innovative insurance schemes have been proposed for pastoral communities of drylands, which are inherently vulnerable to increasing drought risks under changing climates. Many crop-livestock smallholders are trapped in poverty owing to resource constraints, especially cash in time of need. The mobile revolution has provided the means to transfer money to poor rural farmers to maintain/improve livelihoods at the time of crisis. In contrast, where people are moving out of poverty, their demand for livestock products is rising dramatically, and awareness-raising and knowledge transfer through participatory research to safely handle animal-source foods have become increasingly important (Grace et al. 2020b). .

\section{The contributions of Japanese scientists}

Japan used to post Japanese scientists to the ILRAD and ILRI until 2007 as board members (1994 to 2007), and Japan International Research Center for Agricultural Sciences (JIRCAS) and Japan International Cooperation Agency (JICA) long-term experts. Many of these experts were from the National Institute of Animal Health (JIRCAS experts) and universities (JICA experts). Sixteen scientists were posted to the ILRAD between 1974 and 1994, and two board members and four scientists were posted to the ILRI from Japan between 1995 and 2007. However, regardless of the importance of the research mandates, these programs ceased operations, as the ILRI's research priorities shifted from technologies targeting animal production and diseases to broader livelihood risks.

In turn, the Japanese authors of this article worked recently in the ILRI headquarter in Nairobi, Kenya. We worked on projects funded by external grants independent of Japanese financial support. The topics covered by these three scientists were diverse, but the researches were propoor and sought sustainable improvement of livelihoods of livestock and agricultural farmers in developing countries.

For example, Ikegami worked for the Index-Based Livestock Insurance (IBLI) project for climate changeassociated research in ILRI as a post-doctoral scientist from September 2008 to September 2011, as a consultant from October 2011 to March 2013, and as a scientist from April 2013 to February 2018, supported by the United Kingdom Department for International Development, the European Union, the United States Agency for International Development, and the World Bank. Next, Matsumoto belonged to the National Graduate Institute for Policy Studies (GRIPS), which has conducted a 
longitudinal rural household survey in East Africa called RePEAT since 2003. The team dispatched Matsumoto to ILRI using a fund from the Japan Society for the Promotion of Science (JSPS) Global Center for Excellence (GCOE) program, based on collaboration with ILRI under the RePEAT survey project, in order to pursue the project from April 2009 to March 2012. Finally, Makita worked for the Safe Food, Fair Food project in the ILRI funded by the Federal Ministry for Economic Cooperation and Development, Germany (BMZ) as a post-doctoral scientist since 2008, covering eight sub-Saharan African countries. After getting a position as an Associate Professor of Veterinary Epidemiology at Rakuno Gakuen University, Japan, in 2010, Makita continued engaging in the ILRI research projects on food safety and zoonoses as a joint appointment scientist. Since 2012, Makita has worked on several ILRI projects, particularly in Southeast Asia.

\section{Addressing climate variability for resource-poor pastoralists - the potential of IBLI}

\section{Background}

In the arid lands of northern Kenya and southern Ethiopia, livestock is the second-largest productive asset for pastoralists following their human capital. The pastoralists face drought once every 4-5 years and the associated risks are significant in magnitude. When drought occurs, all forage and water for livestock, livestock milk production, and the birth rate of the livestock will decrease. Livestock mortality would increase, frequently reaching a $20-40 \%$ livestock mortality rate. The decreased livestock herd size affects the pastoralists negatively even in the following seasons after the drought.

\section{Hypothesis}

Traditional insurance for livestock mortality is not commercially viable since pastoralists herd livestock in remote and large spaces. It is difficult for insurance companies to verify each animal's death. Index insurance can overcome these problems. Instead of making indemnity payout based on each animal's death as in the case of traditional insurance, index insurance makes indemnity payout based on an index representing the average loss in a region.

Chantarat et al. (2013) applied this idea to livestock mortality owing to droughts in the region and propose their insurance design. The index should have the following properties: 1) closely related to the loss to be insured; 2) not manipulated; 3) timely available, and 4) low costs. What is to be insured is the negative economic shock owing to drought and livestock mortality. They propose predicted livestock mortality based on the normalized difference vegetation index (NDVI) for such an event. NDVI is an index of the greenness on the earth's surface based on measurements remotely captured by satellites. Chantarat et al. (2013) showed that NDVI could explain livestock mortality owing to droughts in the past.

ILRI and its partners launched a commercial IBLI product in January 2010 to mitigate the negative consequences of livestock mortality owing to droughts for pastoralists in northern Kenya and southern Ethiopia. The hypothesis to be tested was that the IBLI would mitigate negative impacts.

\section{Materials and methods}

A baseline household survey was conducted in September 2009 before an insurance company started selling insurance in January 2010 to study insurance uptake and impacts. The number of sample households is 924 , and they are located in 16 sublocations in Marsabit County in northern Kenya. Subsequently, the annual followup surveys were conducted five times. An additional insurance pilot was implemented in the Borena Zone in southern Ethiopia. Borena Zone and Marsabit County share their borders with each other. In the Borena Zone, the baseline household survey was conducted in March 2012, and the initial insurance sale was in August 2012. Five hundred fifteen sample households were located in 17 study areas. Annual follow up surveys were conducted three times. More details of each survey and the data are publicly available at $\mathrm{http} / / /$ data.ilri.org/portal/dataset/ ibli-marsabit-r1 and http://data.ilri.org/portal/dataset/ibliborena-r1.

The major challenge in measuring the impact of the IBLI on household welfare was the endogeneity of insurance uptake. To control this endogeneity, we designed a randomized controlled trial. Since it was challenging to ask insurance companies to sell insurance to particular households or in particular villages and not sell to others, we provided insurance premium discount coupons to households randomly selected from the survey sample households. Most of the impact studies below utilized this discount coupon as an instrumental variable to control the endogeneity of insurance uptake.

\section{Results}

In this section, we review the impacts of the IBLI first and then the determinants of insurance uptake. The impacts of the IBLI were studied using household data. Chantarat et al. (2017) and Janzen et al. (2020) found that IBLI needed subsidies to increase uptake, alter poverty dynamics, and alleviate poverty traps in the region. Jensen et al. (2017a) compared the impacts of the IBLI with those of a conditional cash transfer program called the Hunger 
Safety Net Programme (HSNP), which had been launched in 2009, a year before the IBLI. They found that the ratio of benefits to program costs was comparable between the two, while the marginal cost of an additional client for the IBLI was much smaller than that for HSNP. Jensen et al. (2017b) showed the complementarity between the IBLI and HSNP. The IBLI complemented HSNP in the drought season by decreasing the number of households falling below the poverty line.

The IBLI decreased livestock offtake as a coping strategy against drought (Janzen \& Cater 2019, Noritomo \& Takahashi 2020) and reduced meals during drought (Janzen \& Cater 2019). The IBLI had positive impacts even in non-drought seasons: crowds in the informal risksharing arrangement among pastoralists (Takahashi et al. 2019); and improved subjective well-being (Tafere et al. 2019). Toth et al. (2017) and Matsuda et al. (2019) found that IBLI decreased livestock herd size.

Despite its positive impacts not only in drought but also in non-drought seasons, its voluntary uptake of commercial products has been low, and further study is needed. The determinants of the IBLI uptake were studied using household data. Extension efforts increased potential buyers' understanding of the IBLI but understanding itself did not increase uptake (Takahashi et al. 2016). There was little difference in uptake between male-headed households and female-headed households (Bageant \& Barrett 2017). IBLI's basis risk (the gap between the index and individual household's actual livestock mortality rate) was not small (Jensen et al. 2016), which was the opposite to the results of Chantarat et al. (2013). This risk discouraged insurance uptake (Jensen et al. 2018). Pastoralists purchased insurance opportunistically when they expected a drought (Jensen et al. 2018) or when vegetation condition was not good (Takahashi et al. 2020) rather than purchase insurance consistently over seasons.

\section{Discussion}

The IBLI was expanded from Marsabit County to six other counties in Kenya, and the Kenyan government started providing free IBLI to pastoralists in northern Kenya under the Kenya Livestock Insurance Programme (KLIP) in 2015 (Johnson et al. 2018). The World Food Programme (WFP) also did the same in the Somali region in Ethiopia under the Satellite-Based Index Insurance Programme (SIIPE) since 2018. Despite expanding the IBLI to the larger geographical area and to a public-private partnership, pastoralists' voluntary uptake of commercial IBLI is still low. More studies are needed to determine whether and how voluntary uptake can be increased.

Only the short-term impacts of the IBLI have been studied so far, and studies on the long-term impacts are still missing. The ILRI collected the $7^{\text {th }}$ follow-up survey data in Marsabit in 2020, and forthcoming analysis utilizing ten-year-long panel data is expected to provide evidences on the long-term impacts of the IBLI. Studies based on voluntary uptake might not be able to detect some impact channels owing to low voluntary uptake, and even the detected impact magnitude might be a lower bound. An impact study utilizing public provision of the IBLI, such as KLIP and SIIPE, may overcome this limitation.

Graduation programs that provide not only cash transfers like HSNP above but also a considerable asset transfer at the beginning of programs and continuous training and mentoring on poor households can complement the IBLI. A graduation program can help households move out of poverty, and the IBLI can mitigate adverse shock owing to droughts and prevent households from falling back into poverty. An experiment to study this complementarity has been implemented in Samburu County, Kenya since 2018.

\section{Addressing multi-dimensional poverty - the mobile revolution for financial inclusion}

\section{Background}

Mobile phones have rapidly spread in the last two decades, even in the African continent, where the poorest countries are concentrated. The number of mobile phone subscriptions per 100 people in the sub-Saharan African region became 82.4 in 2018 from 1.7 in 2000, implying that mobile phones are disseminated to every region and every social class. The spread of mobile phones has made it possible to deliver voice and text information to remote locations at low cost and has triggered various services using mobile phones as platforms. In particular, electronic payment services using short messages of mobile phones called "mobile money" have been spreading tremendously in sub-Saharan Africa and changing people's lives. This significant change involves both the wealthy in cities and the poor in rural areas, where people have previously had minimal access to financial services. Currently, rural residents in many African countries send and deposit money easily, quickly, and safely using mobile money. This rapid spread of mobile money in rural Uganda is closely related to the lifestyle of rural residents besides the rapid development of mobile communication and financial infrastructure. The majority of rural residents are small-scale farmers engaged in settled agriculture with a small piece of land. It is quite common for rural households to send their family members to towns for jobs. Mobile money has become an indispensable tool for migrant workers to send remittances to their rural families. In addition, borrowing and lending money between 
relatives and friends are common. The need for means of remittances between individuals has been high in rural areas. Before the advent of mobile money, there were only inefficient and unsecured means for remittance such as wire transfer at the post office, remittance entrusted to an acquaintance, or the migrant him/herself bringing it when he or she returned home. Mobile money has changed the situation completely. This section summarizes our research findings on mobile money dissemination and its impact on Uganda's rural households.

\section{Hypothesis}

The first mobile money service in Uganda was launched in March 2009 by Mobile Telephone Network (MTN)-Uganda, following the massive success of Safaricom's M-PESA in Kenya. Other network operators such as Airtel, Uganda Telecom, Warid Telecom, and Orange Uganda, followed MTN and started their mobile money services. Since the establishment of mobile money services, the number of subscribers has been steadily increasing. Our data show that whereas less than $1 \%$ of the sample households in rural Uganda used mobile money in 2009 , the number of users rapidly increased and reached $72 \%$ in 2015 . We hypothesize that this dramatic change in the dissemination of mobile money positively affects the livelihood of rural households through frequent and timely financial transactions via family and friends networks.

\section{Materials and methods}

During the dramatic change in the mobile environment in Uganda, we had a chance to closely observe the lives of rural residents through a household survey. Our research team had been conducting a longitudinal rural household survey in Uganda since 2003, as a part of the Research on Poverty, Environment, and Agricultural Technology (RePEAT) (Yamano et al. 2011). The latest three waves covered the period of the change in the mobile environment. Thus, the database was ideal for analyzing the effects of mobile money dissemination. The survey covered 94 rural communities in the eastern, central, and western regions of Uganda and collected detailed socio-economic information of 10 households in each community. Utilizing household-level data, we applied the difference-in-differences method to evaluate the impact of mobile money adoption on household welfare, maternal healthcare access, and the educational investment of children of rural households in Uganda.

\section{Results}

Munyegera \& Matsumoto (2016) found a positive and significant impact of mobile money use on household welfare measured by real per capita consumption. The facilitation of remittances by mobile money brought about this positive influence. The user households were more likely to receive remittances more frequently (5.5 times per year on average), and the total value received was twice as high as that of non-user households, equivalent to approximately $15 \%$ of the annual expenditure of households. Munyegera \& Matsumoto (2018) also found that using mobile money services increased the frequencies and amounts of saving and borrowing.

Cash flow through mobile money eases the credit constraints of rural households. Hence, we expected positive impacts in several aspects of their lives other than consumption. Egami \& Matsumoto (2020) examined the impact of mobile money on access to health services, particularly maternal healthcare. We found suggestive evidence that mobile money adoption increased the take-up of antenatal care. In addition, the heterogeneity analysis showed that mobile money brought a larger benefit to geographically challenged households. Financial inclusion through mobile money brought about better healthcare access for women in rural and remote areas in a developing country in sub-Saharan Africa. Tabetando \& Matsumoto (2020) examined the impact of mobile money adoption on households' educational investment for their children, especially when their members were sick. We found that mobile money user households mitigated the negative impact of health shocks on educational investment, measured by per-child educational expenses. Such positive impacts were observed particularly among geographically challenged households with limited access to financial services before disseminating mobile money.

\section{Discussion}

Mobile money has spread rapidly in many African countries. This change enabled rural smallholder farmers to receive, remit, deposit, and borrow money quickly and easily. Although sub-Saharan African countries still have serious poverty problems, many of them have developed mobile communication and financial infrastructure, and more people have been involved in this dramatic change. They have better access to financial services. There is no doubt that private businesses will be booming corresponding to this mobile revolution, coupled with improvements in transportation infrastructure. We strongly believe that the light of hope is gradually shining on the future of Africa. With the hope that the era of Africa will come, we as researchers would like to continue observing what is happening in Africa. 
Addressing human health risks for animal source food-borne diseases - the role of participatory research

\section{Background}

Food-borne diseases (FBDs) bear an enormous health burden, particularly in developing countries, and animal source foods, which provide rich nutrition to people, are the major food source. The FBDs are caused by microbial pathogens and toxins produced by bacteria and fungi. In developing countries, informal food value chains, where sanitary inspections are not taken in place, dominate. The risks for the FBDs are increasing, as the livestock sector grows along with economic growth. The global burden of the FBDs in 2010 was estimated at 33 million disabilityadjusted life years (DALYs), which is comparable to 66 million DALYs and 33 million DALYs of tuberculosis and malaria in 2019 (WHO 2021).

\section{Hypothesis}

Food safety risk analysis, initially developed to ensure transparency in international food trades, has been very useful in understanding and mitigating food safety risks in developed countries. The application of food safety risk analysis is a big challenge in developing countries owing to the dominance of informal food value chains that do not generate passive surveillance data and are also difficult to control. The ILRI proposed a hypothesis that participatory methods in risk analysis would enable its application in developing countries. Participatory risk analysis involves participatory methods such as participatory rural appraisal (PRA), rapid rural appraisal (RRA), and key-informant interviews in any of the steps. For example, an informal value chain is quite complex and challenging to capture; however, an RRA involving games was found useful in understanding the structures of the informal value chain and cooking and consumption behaviors. A participatory approach was also useful in risk communication; government authorities recognized the importance of informal markets as major drivers of the economy and food distribution and showed interest in policy discussions on food safety.

\section{Materials and methods}

In the early 2000s, the ILRI began a program on improving human health through livestock research in three areas: (1) animal-source foods for nutrition, (2) zoonoses, and (3) FBDs. The program on human health was the first CGIAR group with an explicit food safety mandate and related food safety concepts with informal value chains that start from smallholder producers, promoting economic development and public health while understanding the roles of traditional informal markets and food processing. Gender and environmental aspects were well incorporated in food safety researches and showed the importance of the multi-sectoral approach in this emerging topic. Food safety research has become more prominent with the development of the CGIAR Research Programme (CRP) on Agriculture for Nutrition and Health (A4NH). A4NH brought together portfolios of aflatoxin research led by the International Institute of Tropical Agriculture (IITA), ICRISAT, International Food Policy Research Institute (IFPRI), and ILRI, and a portfolio of research on animal-source foods led by ILRI (A4NH 2011). The rich history of 47 years of research by the ILRI has been published and available online (McIntire \& Grace 2020).

Safe Food, Fair Food project (Grace et al. 2010) developed and applied participatory risk analysis in such informal value chains in eight sub-Saharan African countries between 2008 and 2012, using Codex Alimentarius Commission (CAC) risk analysis comprising risk assessment, risk management, and risk communication (CAC 2013), with four steps of risk assessment: hazard identification, hazard characterization, exposure assessment, and risk characterization (Figure 1). This approach has been expanded to other African and Asian countries since 2012.

\section{Results}

Here, two examples out of over 50 studies in Asia and Africa are provided.

(1) Traditional yogurt making is reducing the risk of staphylococcal food poisoning in Ethiopia

In Debre Zeit, Ethiopia, a risk assessment for staphylococcal food poisoning owing to consumption

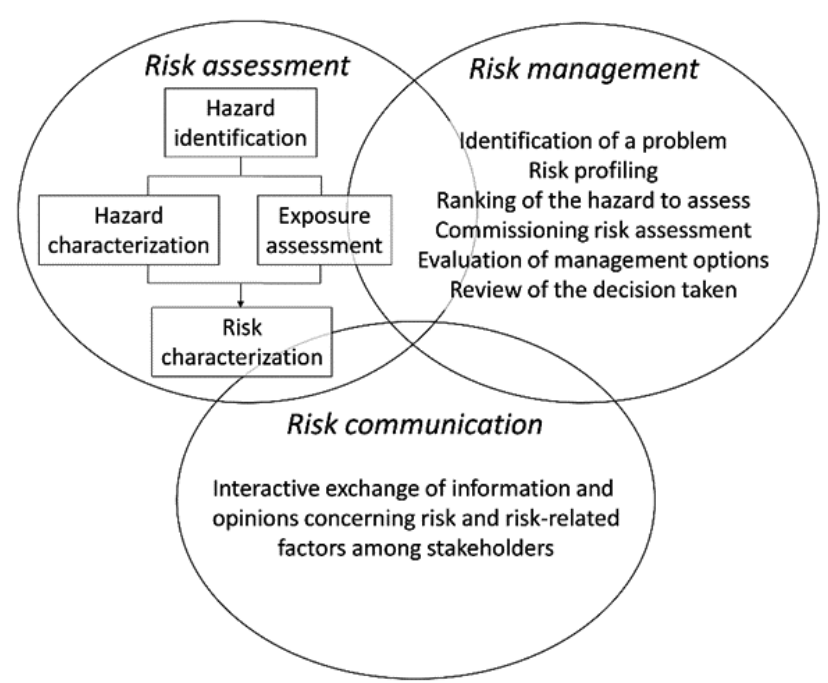

Fig. 1. Codex Alimentarius Risk Analysis framework (CAC., 2013) 
of informally marketed milk and home-made yogurt was conducted (Makita et al. 2012). Staphylococcal food poisoning, characterized by the sudden onset of nausea, vomiting, abdominal cramps, and diarrhea, is caused by a minimal amount of enterotoxin produced by Staphylococcus aureus. An RRA with dairy stakeholders was conducted to elucidate the structure of dairy value chains, and a questionnaire survey quantified the chains. Half of the untreated liquid milk produced went to formal milk processing. In contrast, the other half was the sources of home consumption, farm gate sales, restaurants and cafeterias, and traditional processing for sale in urban areas. At the farm level, 43.5\% (74/170) of milk samples were contaminated with $S$. aureus, and the prevalence was higher at milk collection centers $(72 \%, 18 / 25)$. According to the interviews, $68.2 \%(116 / 170)$ of farmers and $64.0 \%$ (16/25) of consumers boiled the milk before consumption, but others did not. This was surprising, but it was found that traditionally, raw milk is fermented to make yogurt at home. A computer simulation showed that the annual risk of staphylococcal poisoning due to consumption of milk and home-made yogurt was 20.0 per 1000 people, and the risk was reduced by $93.7 \%$ by traditional fermentation. The factors influencing the risk were bacteria concentration at milking and temperature of milk stored. This suggested that bovine mastitis control, milking mastitis cows after healthy cows, and introducing the refrigerator at milk collection centers would further reduce the risk, even without changing traditional food culture.

(2) Improvement of pork safety in smallholder pig value chains in Vietnam

The PigRISK project, "Reducing disease risks and improving food safety in smallholder pig value chains in Vietnam", funded by the Australian Centre for International Agricultural Research (ACIAR), Australia, and run by the ILRI, conducted a series of studies on smallholder pig value chains. Pig value chains comprise farms, slaughterhouses, the transportation of carcasses, and markets. In northern Vietnam, Salmonella prevalence was $36.1 \%, 38.9 \%$, and $44.7 \%$ on pig pen floors, pig carcasses in slaughterhouses, and pork cuts in pork shops, respectively. Risk factor analyses suggested that low biosecurity at each step facilitated Salmonella contamination. The cooking and consumption patterns of the households were further studied. As a result, the annual incidence rate of salmonellosis is rather high $(17.7 \%)$ (Sinh et al. 2017; Sinh et al. 2019). Intervention programs are ongoing, and behavioral economics such as nudges (Hennessey et al. 2020) are being studied to understand best-bet policy supports.

In addition, training and capacity building for the ILRI's national partners were important activities through Kohei Makita's participation. A Ph.D. student from Vietnam was supervised and defended his Ph.D. at Rakuno Gakuen University in 2018.

\section{Discussion}

Participatory risk analysis is applied to broader problems (bacterial FBDs to toxins, environmental hazards, and malnutrition), more expansive geographical areas, and implementation and monitoring of intervention programs. It has the potential to elucidate the burden of diseases in humans in resource-poor countries, improving animal health and livestock productivity, and facilitating One Health by connecting multiple sectors through participation.

\section{Conclusion}

This article summarizes the research activities of the three ILRI researchers. These research topics livestock insurance for extreme climatic events, coping mechanisms in household economy among farmers, and participatory risk analysis - were diverse. However, these topics represent the direction of recent ILRI's strategies: provision of sustainable solutions to ensure farmers' livelihoods, and the health of people in developing countries. Currently, the world is suffering from the pandemic of the coronavirus disease (COVID-19), and the ILRI is one of the co-implementers of the CGIAR COVID-19 Hub launched in June 2020, and hosted by A4NH. The COVID-19 Hub supports governments by helping response, recovery and resilience measures. Owing to the COVID-19 pandemic, the interest in zoonotic diseases and One Health are increasing globally, and global warming is an inevitable threat. The ILRI remains active in generating and consolidating multifaceted scientific evidence to help governments tackle livestock and human health challenges.

Japan used to send researchers to ILRI. Considering the growing global importance of the issues related with livestock, as summarized in this review, international cooperation through ILRI should be revitalized.

\section{References}

A4NH (2011) Agriculture for improved nutrition and health: full proposal. IFPRI, Washington, DC.

Bageant, E. R. \& Barrett C. B. (2017) Are There Gender Differences in Demand for Index-Based Livestock Insurance? J. Dev. Stud., 53, 932-952.

Black, S. J. (2020) Control of pathogenesis in African animal trypanosomiasis: A search for answers at ILRAD, ILCA and ILRI, 1975-2018. In The impact of the International Livestock Research Institute. Eds. McIntire, J. \& Grace, D., 
CABI, Oxfordshire, UK, 103-147.

Blümmel, M. et al. (2020) Multidimensional crop improvement by ILRI and partners: drivers, approaches, achievements, and impact. In The impact of the International Livestock Research Institute. Eds. McIntire, J. \& Grace, D., CABI, Oxfordshire, UK, 480-505.

CAC. (2013) Codex Alimentarius Commission procedural manual 21st edition. Rome.

Chantarat, S. et al. (2013) Designing Index-Based Livestock Insurance for Managing Asset Risk in Northern Kenya. $J$. Risk Insur., 80, 205-237.

Chantarat, S. et al. (2017) Welfare Impacts of Index Insurance in the Presence of a Poverty Trap. World Dev., 94, 119-38.

Duncan, AJ. et al. (2020) The impact of CGIAR Centre research on use of planted forages by tropical smallholders. In The impact of the International Livestock Research Institute. Eds. McIntire, J. \& Grace, D., CABI, Oxfordshire, UK, 450479.

Egami, H. \& Matsumoto, T. (2020). Mobile money use and healthcare utilization: Evidence from rural Uganda. Sustainability, 12, 3741. https://doi.org/10.3390/su12093741

Ericksen, P. et al. (2020) Rangeland ecology. In The impact of the International Livestock Research Institute. Eds. McIntire, J. \& Grace, D., CABI, Oxfordshire, UK, 395-422.

Grace, D. et al. (2010) Safe Food, Fair Food: Participatory Risk Analysis for improving the safety of informally produced and marketed food in sub-Saharan Africa. Rev. Afric. Santé Product. Animal., 8, 3-11.

Grace, D. et al. (2020a) Tsetse and trypanosomiasis control in West Africa, Uganda and Ethiopia: ILRI's role in the field. In The impact of the International Livestock Research Institute. Eds. McIntire, J. \& Grace, D., CABI, Oxfordshire, UK, 148163.

Grace, D. et al. (2020b) Food safety and nutrition. In The impact of the International Livestock Research Institute. Eds. McIntire, J. \& Grace, D., CABI, Oxfordshire, UK, p338-365.

Hanson, J. et al. (2020) Forage diversity, conservation and use. In The impact of the International Livestock Research Institute. Eds. McIntire, J. \& Grace, D., CABI, Oxfordshire, UK, 423-449.

Hennessey, M. et al. (2020) Exploring the potential of using nudges to promote food hygiene in the pork value chain in Vietnam. Prev. Vet. Med., 181, 105003.

ILRI (2010) Livestock researchers announce the eradication of rinderpest. Audio. Nairobi, Kenya, ILRI [https://hdl.handle. net/10568/2597].

ILRI (2021) Prosperity. In Research themes. ILRI homepage. [https://www.ilri.org/research/themes/prosperity] Accessed on May 5, 2021.

Janzen, S. A. \& Carter, M. R. (2019) After the Drought: The Impact of Microinsurance on Consumption Smoothing and Asset Protection. Ame. J. Agri. Econ., 101, 651-671.

Janzen, S. A. et al. (2021) Can insurance alter poverty dynamics and reduce the cost of social protection in developing countries? J. Risk Insur., 88, 293-324.

Jensen, N. et al. (2016) Index insurance quality and basis risk: Evidence from Northern Kenya. Ame. J. Agri, Econ., 98, 1450-1469.

Jensen, N. et al. (2017a) Cash transfers and index insurance: A comparative impact analysis from northern Kenya J. Dev. Econ., 129, 14-28.
Jensen, N. et al. (2017b) Integrating Social Protection Strategies for Improved Impact: A Comparative Evaluation of Cash Transfers and Index Insurance in Kenya. The Geneva Papers on Risk and Insurance - Issues and Practice, 42, 675-707.

Jensen, N. et al. (2018) How basis risk and spatiotemporal adverse selection influence demand for index insurance: Evidence from northern Kenya. Food Policy, 74, 172-198.

Johnson, L. et al. (2018) Competing Expectations in an IndexBased Livestock Insurance Project. J. Dev. Stud., 55, 12211239.

Makita, K. et al. (2012) Risk assessment of staphylococcal poisoning due to consumption of informally-marketed milk and home-made yoghurt in Debre Zeit, Ethiopia. Int. J. Food Microbiol., 153, 135-141.

Matsuda, A. et al. (2019) Direct and indirect impact of indexbased livestock insurance in Southern Ethiopia. The Geneva Papers on Risk and Insurance - Issues and Practice, 44, 481502.

McIntire, J. et al. (2020) African livestock systems research, 1975-2018. In: McIntire J and Grace D, eds. The impact of the International Livestock Research Institute. Eds. McIntire, J. \& Grace, D., CABI, Oxfordshire, UK, 515-600.

McIntire, J. \& Grace, D. (2020) The Impact of the International Livestock Research Institute. Nairobi, Kenya: ILRI, and Wallingford, UK: CABI. https://cgspace.cgiar.org/handle/ $10568 / 108972$

Munyegera, G. K. \& Matsumoto, T. (2016). Mobile Money, Remittances, and Household Welfare: Panel Evidence from Rural Uganda. World Dev., 79, 127-137. https://doi. org/10.1016/j.worlddev.2015.11.006

Munyegera, G. K. \& Matsumoto, T. (2018). ICT for financial access: Mobile money and the financial behavior of rural households in Uganda. Rev. Dev. Econ., 22, 45-66. https:// doi.org/10.1111/rode.12327

Noritomo, Y. \& Takahashi, K. (2020) Can Insurance Payouts Prevent a Poverty Trap? Evidence from Randomized Experiments in Northern Kenya. J. Deve. Stud., 56, 20792096

Rege, J.E.O. et al. (2020) Livestock genetics and breeding. In The impact of the International Livestock Research Institute. Eds. McIntire, J. \& Grace, D., CABI, Oxfordshire, UK, P59102.

Sinh, D.X. et al. (2017) Quantitative risk assessment of human salmonellosis in the smallholder pig value chains in urban of Vietnam. Int. J. Public Health, 62, S93-102.

Sinh, D.X. et al. (2019) Risk factors associated with Salmonella spp. prevalence along smallholder pig value chains in Vietnam. Int. J. Food Microbiol., 290, 105-115.

Smith J. (2020) A note from ILRI Director General Jimmy Smith. Preface. In The impact of the International Livestock Research Institute. Eds. McIntire, J. \& Grace, D., CABI, Oxfordshire, UK.

Tabetando, R. \& Matsumoto, T. (2020). Mobile Money, Risk Sharing, and Educational Investment: Panel Evidence from Rural Uganda. Rev. Dev. Econ., 24, 84-105. https://doi. org/10.1111/rode. 12644

Tafere, K. et al. (2019) Insuring well-being? Buyer's remorse and peace of mind effects from insurance. Am. J. Agri. Econ., 101, 627-650.

Takahashi, K. et al. (2016) Experimental Evidence on the Drivers of Index-Based Livestock Insurance Demand in Southern 
Ethiopia. World Dev., 78, 324-340.

Takahashi, K. et al. (2019) Index-Based Livestock Insurance, Social Network, and Informal Risk Sharing: Evidence from Rural Ethiopia. Am. J. Agr. Econ., 101, 672-691.

Takahashi, K. et al. (2020) Understanding Pastoralists' Dynamic Insurance Uptake Decisions: Evidence from Four-year Panel Data in Ethiopia. Food Policy, 95, 101910.

Toye, P. et al. (2020) The management and economics of East Coast Fever. In The impact of the International Livestock Research Institute. Eds. McIntire, J. \& Grace, D., CABI,
Oxfordshire, UK, 239-273.

WHO (2021) Global Health Estimates 2019: DALYs by age, sex and cause. The Global Health Observatory. World Health Organization website.

[https://www.who.int/data/gho/data/themes/mortality-andglobal-health-estimates/global-health-estimates-leadingcauses-of-dalys] Accessed on May 5, 2021.

Yamano, T. et al. (eds) (2011). Emerging Development of Agriculture in East Africa: Markets, Soil, and Innovations, Springer. https://www.doi.org/10.1007/978-94-007-1201-0 